\title{
Research on the Fatigue Properties of High Strength Concrete after Exposure to High Temperature under Low Cyclic Compressive Loading
}

\author{
Linhao Wang, ${ }^{1}$ Haijing Gao $\left(\mathbb{D},{ }^{2}\right.$ Haibiao Gao, ${ }^{3}$ and Zhili Luo ${ }^{1}$ \\ ${ }^{1}$ College of Architecture and Civil Engineering, Taiyuan University of Technology, Taiyuan, China \\ ${ }^{2}$ Wangzuo Township People's Government of Fengtai District of Beijing Municipality, Beijing 10007, China \\ ${ }^{3}$ Jiangling Motors Co., Ltd., Taiyuan, China \\ Correspondence should be addressed to Haijing Gao; baboon007@126.com
}

Received 28 February 2018; Accepted 15 April 2018; Published 23 May 2018

Academic Editor: Aly M. Aly

Copyright ( 2018 Linhao Wang et al. This is an open access article distributed under the Creative Commons Attribution License, which permits unrestricted use, distribution, and reproduction in any medium, provided the original work is properly cited.

\begin{abstract}
By using an electrohydraulic servo fatigue testing machine, fatigue tests were performed on C60 high strength concrete (HSC) under low cyclic compressive loading after undergoing normal temperature, $200^{\circ} \mathrm{C}, 400^{\circ} \mathrm{C}, 600^{\circ} \mathrm{C}$, and $800^{\circ} \mathrm{C}$. Failure patterns of high strength concrete under low cyclic compressive loading were observed. The influence of the high temperature process on the static elastic modulus of high strength concrete was analyzed. By studying the development law of fatigue strain, regression equations of fatigue strain after different high temperatures were established. Furthermore, the fatigue deformation modulus ratio was defined as the damage variable and the relationship models between the high temperature process and the fatigue damage were established. It provides the experimental foundation for fatigue damage analysis of high strength concrete in objective working conditions, which includes repeated loading and different high temperature processes.
\end{abstract}

\section{Introduction}

High strength concrete (HSC) has been widely used with the increasing complex structures of modern architecture. For instance, the Petronas Twin Towers in Kuala Lumpur City Centre, Malaysia, used C80 HSC. 311 South Wacker Drive in Chicago, USA, used C95 HSC. Two Union Square Building in Seattle, USA, used C135 HSC, Television Culture Center of China (TVCC), Shanghai World Financial Center (SWFC), adopted C60 HSC. In practice, concrete structures not only undertake static loading and the cyclic loading (vehicle loads, wind loads, wave loads, etc.), but also may suffer high temperature processes caused by fire or other reasons, which further results in serious damage of its structural properties.

At present, researches on mechanical properties of HSC after exposure to high temperature have been deeply carried out worldwide. Most studies [1-10] focused on the basic properties of HSC, such as appearance, mass, tensile strength, failure pattern, multiaxle strength, and stress-strain curve; those studies established the formula for failure criterion of HSC in multiaxial stress state. However, the study on fatigue behavior of HSC after exposure to high temperature has not been carried out yet, especially after exposure to different high temperature processes. Several researches were concentrated on uniaxial fatigue behavior of ordinary concrete after exposure to high temperature [11-13]. In those studies, the tensile fatigue behavior of concrete under constant amplitude cyclic load after $100^{\circ} \mathrm{C}$ and $200^{\circ} \mathrm{C}$ has been investigated, the static performance of concrete has been analyzed, and the relationship between total strain growth rates at the second stage and fatigue life has been given. Nevertheless, the relationship model between the high temperature process and the fatigue damage of HSC failed to be established, and huge gap in the fatigue damage evaluation of fire-damaged HSC structure remains.

This paper presents the variation discipline of appearance, static elastic modulus, fatigue strain, residual strain, and fatigue deformation modulus of C60 HSC structure which was tested at various stress ratios after suffering room temperature, $200,400,600$, and $800^{\circ} \mathrm{C}$. The static load test and 
fatigue test were performed with electrohydraulic servo pressure machine and electrohydraulic servo fatigue machine, respectively. And the relationship models between the high temperature process and the fatigue damage are established, those provide reference to fatigue damage assessment of high strength concrete subjected to different high temperature processes.

\section{Materials and Experimental Procedures}

2.1. Materials and Mix Proportions. The materials used in this investigation are standard cube specimens, as shown in Figure 1(b), which are made of C60 concrete (the matching ratio is shown in Table 1$)$. Heating temperature was room temperature $\left(20^{\circ} \mathrm{C}\right), 200^{\circ} \mathrm{C}, 400^{\circ} \mathrm{C}, 600^{\circ} \mathrm{C}$, and $800^{\circ} \mathrm{C}$ respectively. Each set of specimens are constantly heated for $0.5 \mathrm{~h}$, $1 \mathrm{~h}, 2 \mathrm{~h}$, and $3 \mathrm{~h}$ after reaching the specified temperature.

2.2. Apparatus and Testing Methods. The high temperature test was carried out in a box-type resistance furnace, as shown in Figure 1(a), whose size is $300 \mathrm{~mm} \times 500 \mathrm{~mm} \times 200 \mathrm{~mm}$. The maximal permitted temperature of resistance for furnace is $1000^{\circ} \mathrm{C}$, and the temperature control precision is $\pm 1^{\circ} \mathrm{C}$. After specimens were put into the resistance furnace, the temperature gradually rose from the room temperature to the preset temperature in a rate of $10^{\circ} \mathrm{C} / \mathrm{min}$ [14], and the temperature was maintained constantly for a certain time. In order to prevent the specimens from bursting during heating process, the specimens were wrapped around with high temperature barbed wire.

The static load test was carried out with the electrohydraulic servo pressure machine, as shown in Figure 1(c). The axis of specimen should be coincident with the axis of the machine panel before test, then repeatedly preloading and unloading the specimen three times with $20 \%$ of the upper limit load with $20 \%$ of the upper limit load; then pressure was applied at a rate of $0.3 \mathrm{MPa} / \mathrm{s}-0.8 \mathrm{MPa} / \mathrm{s}$ on the specimen until failure, and the ultimate bearing capacity of the specimen was obtained.

The fatigue test was carried out with an electrohydraulic servo fatigue machine, as shown in Figure $1(\mathrm{~d})$. The fatigue load was applied by a $500 \mathrm{kN}$ actuator in the vertical direction; the pressure is monitored by the voltmeter. The GTC 450 full digital electrohydraulic servo controller was used to control and collect data in real time. Cyclic loading waveform was sine wave, the minimum stress level $S_{\min }$ (the ratio of minimum lateral compressive stress $\sigma_{\min }$ and tensile strength $f_{t}$ ) was 0.1 , and the maximum stress levels $S_{\max }$ were $0.80,0.85$, and 0.90 , respectively. Each principal stress direction must be perpendicular to the surface of the specimen. The deformation was measured with a $50 \mathrm{~mm}$ foil resistive strain gauge, which was applied to the two free surfaces of the specimen.

All tests were carried out by using three layers of plastic films spread with butter as the friction-reducing pad to ensure the test was conducted with few friction.

\section{Test Results and Discussion}

\subsection{Experimental Results and Analysis}

3.1.1. Apparent Appearance. HSC specimens have a series of apparent characteristics changes during the heating process from the room temperature $\left(20^{\circ} \mathrm{C}\right)$ to the specified temperature, including the color variation, crack propagation, scaling, broken corners, and looseness, as shown in Figure 2 and Table 2 . When the temperature exceeded $200^{\circ} \mathrm{C}$, irritating odor was generated. When the temperature exceeded $400^{\circ} \mathrm{C}$, water mist emitted from the furnish door and irritating odor increased; when temperature reached $600^{\circ} \mathrm{C}$, the water mist mostly disappeared and remarkable sound of bursting came out occasionally of box-type resistance furnace. When the heating process finished and the furnace door was opened, there were water droplets on the upper and lower sides of the furnace door.

As shown in Figure 2, the color of cooled specimens had no significant difference between before and after suffering $200^{\circ} \mathrm{C}$ [14]. The whole or part of specimens appeared rust red after suffering $400^{\circ} \mathrm{C}$ for one hour, which had a significant contrast with the color of the corresponding specimen at the room temperature. After heating up for 3 hours, the red disappeared and the light gray appeared on the specimen surface. Crack increased, but it did not spread across the entire surface. A small number of specimens had peeled pieces and broken corners, but most of the specimens kept a unbroken appearance. A small number of specimens had burst during the heating process, which caused rough section area, many holes, and cracks. After suffering $800^{\circ} \mathrm{C}$, the specimens' appearance turned into offwhite, and some coarse cracks came out, and the overall structure was relatively loose.

It was analyzed that, at $400^{\circ} \mathrm{C}$, hydration of calcium ferrite $\left(\mathrm{CaO} \cdot \mathrm{Fe}_{2} \mathrm{O}_{3} \cdot \mathrm{H}_{2} \mathrm{O}\right)$ in the concrete has a chemical reaction with $\mathrm{Ca}(\mathrm{OH})_{2}$, which results in reddish-brown $\mathrm{Fe}(\mathrm{OH})_{3}$ [12]. With $600^{\circ} \mathrm{C}, \mathrm{Fe}(\mathrm{OH})_{3}$ was decomposed into iron oxide and the red disappears.

3.1.2. Failure Mode. The failure modes of HSC under low cyclic compressive loading after different high temperature processes are shown in Figure 3. Due to suffering the high temperature, there were already some visible cracks on the specimens surface before loading. During $600^{\circ} \mathrm{C}$ procedure, some specimens sustained brittle failure and burst with splitting sound. This is because the strength of cement gel is close to the strength of coarse aggregate, which makes the development of cracks unable to be blocked and buffered by coarse aggregate like ordinary concrete. When reaching the peak stress, the energy accumulated inside is released in a rapid and violent manner and it made the specimen burst. It was obvious to see that, under uniaxial compressive stress, the HSC specimen split into multiple small cylinders. The failure surface of HSC was parallel to the compressive stress direction and perpendicular to the free surface, causing formation of one or more failure surfaces, and this phenomenon is called columnar damage. The failure mode of HSC was columnshaped conquassation, and the specific form is related to the applied stress level. Some specimens even show the failure mode of bulk fragments. This conclusion is consistent with the experimental results of $\mathrm{Lv}$ [12] and $\mathrm{Xu}$ [15].

3.1.3. Relative Compressive Strength. Through the static test, the compressive strength of the specimen after the antifriction at room temperature was $49.6 \mathrm{MPa}$, and the compressive 


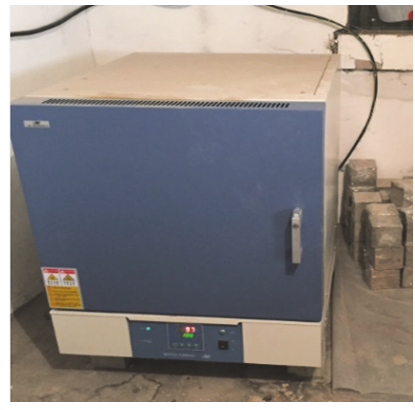

(a)

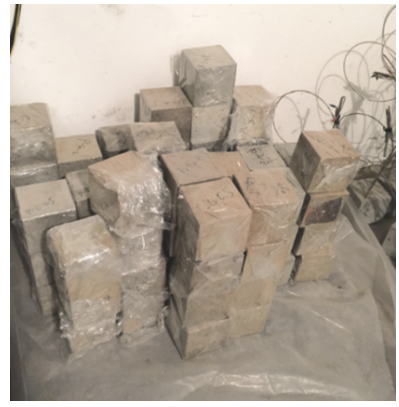

(b)

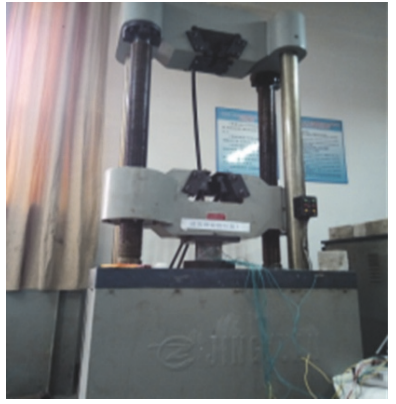

(c)

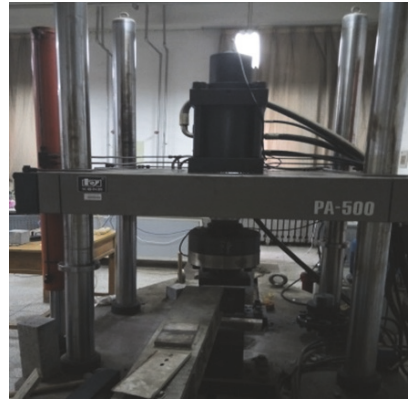

(d)

FIGURE 1: Apparatus and specimens: (a) box-type resistance furnace; (b) specimens; (c) electrohydraulic servo pressure machine; (d) electrohydraulic servo fatigue machine.

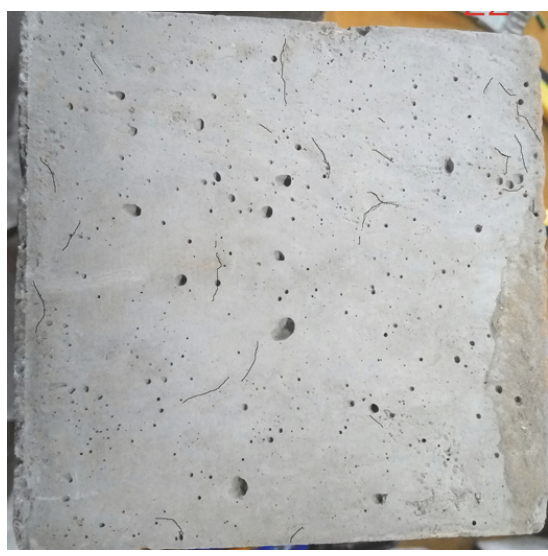

(a)

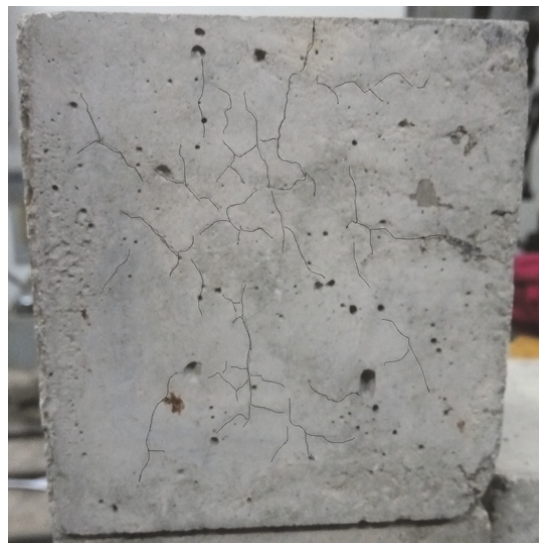

(d)

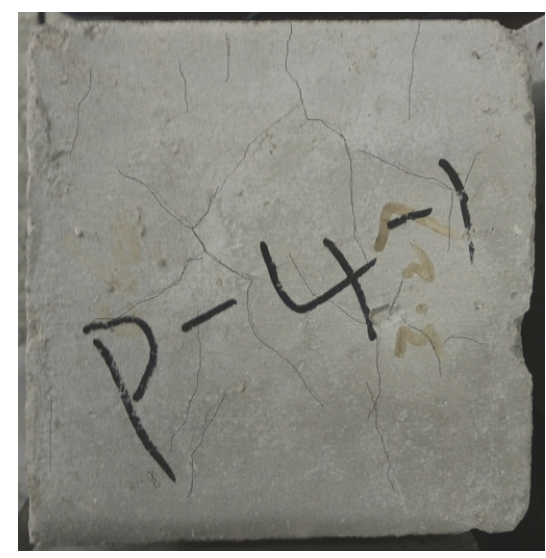

(b)

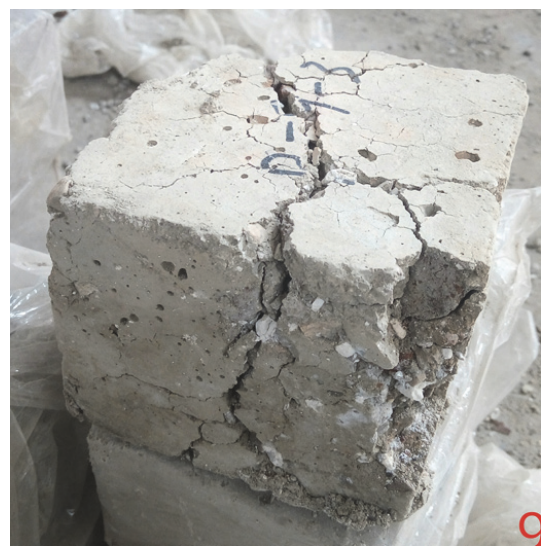

(e)

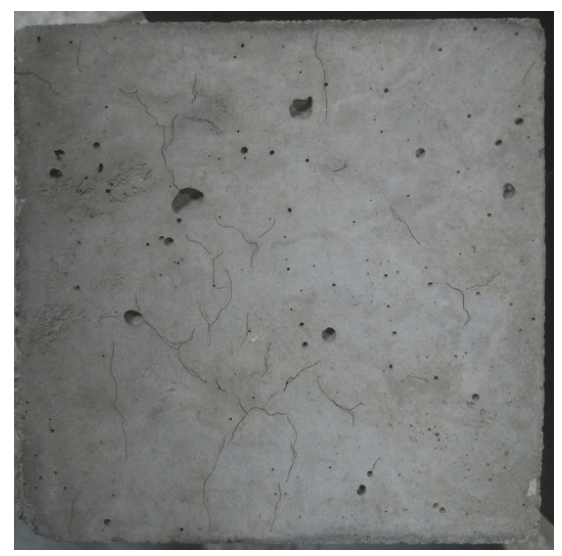

(c)

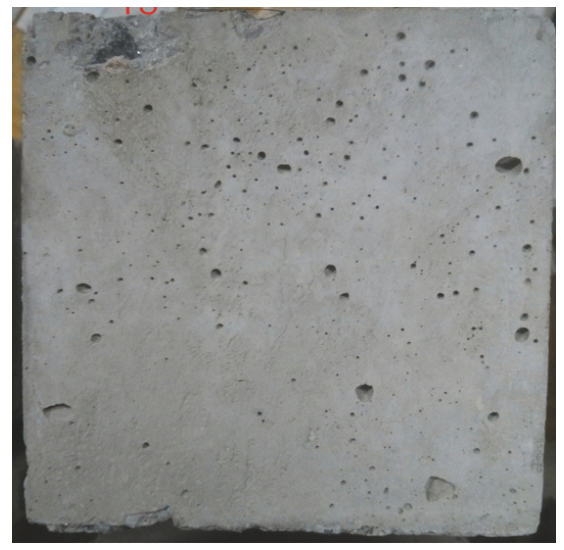

(f)

Figure 2: The apparent changes of HSC after different high temperature processes: (a) P-2-2; (b) P-4-1; (c) P-4-3; (d) P-6-0.5; (e) P-8-3; (f) normal temperature $\left(\mathrm{P}-\mathrm{X}-\mathrm{X}\right.$ indicates fatigue test, heating temperature $\left(\times 100^{\circ} \mathrm{C}\right)$, holding time $(\mathrm{h})$, such as $\mathrm{P}-2-2$ indicates holding $2 \mathrm{~h}$ after heating up to $200^{\circ} \mathrm{C}$ ).

TABLE 1: Mix proportions of HSC.

\begin{tabular}{lccccc}
\hline Cement: $\mathrm{kg} / \mathrm{m}^{3}$ & Sand: $\mathrm{kg} / \mathrm{m}^{3}$ & Gravel: $\mathrm{kg} / \mathrm{m}^{3}$ & Water: $\mathrm{kg} / \mathrm{m}^{3}$ & Water-reducing agent: $\mathrm{kg} / \mathrm{m}^{3}$ & Water-to-binder ratio \\
\hline 510 & 720 & 1040 & 163 & 11 & 0.32 \\
\hline
\end{tabular}




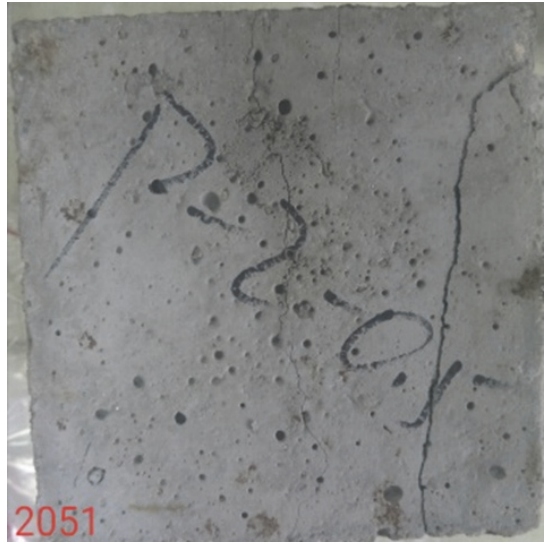

(a)

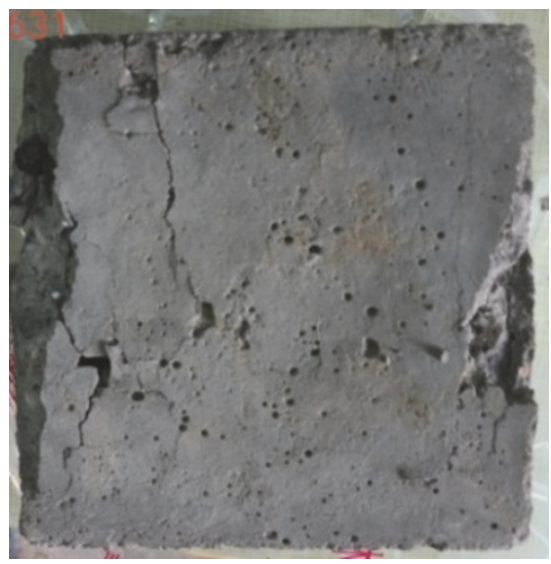

(d)

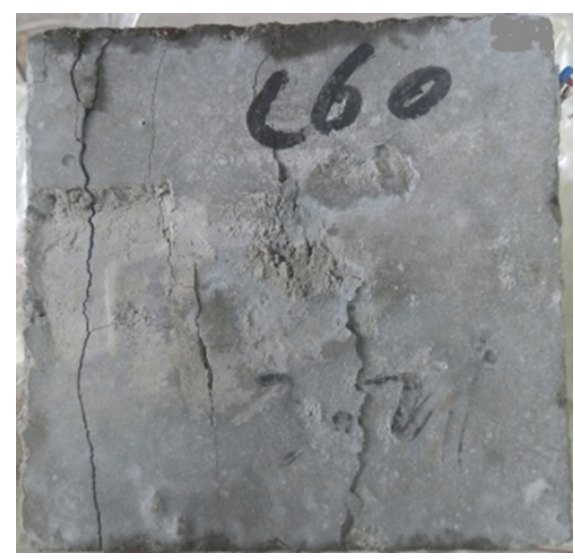

(b)

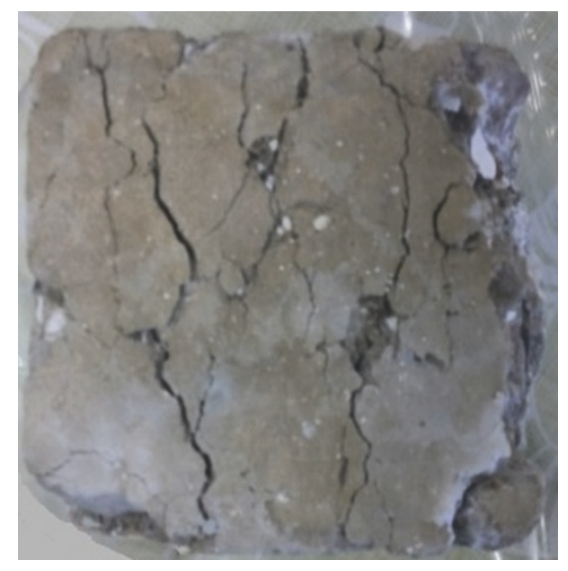

(e)

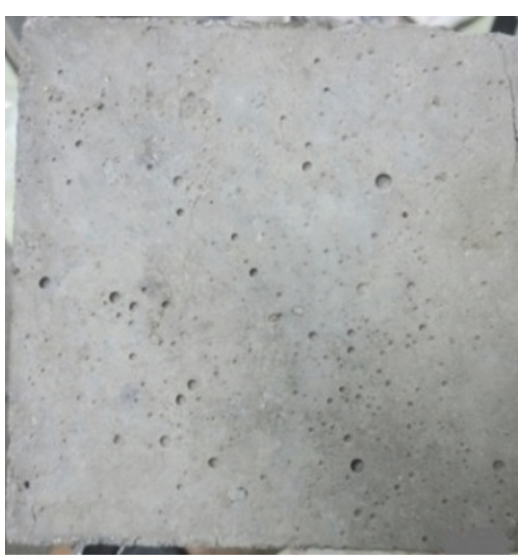

(c)

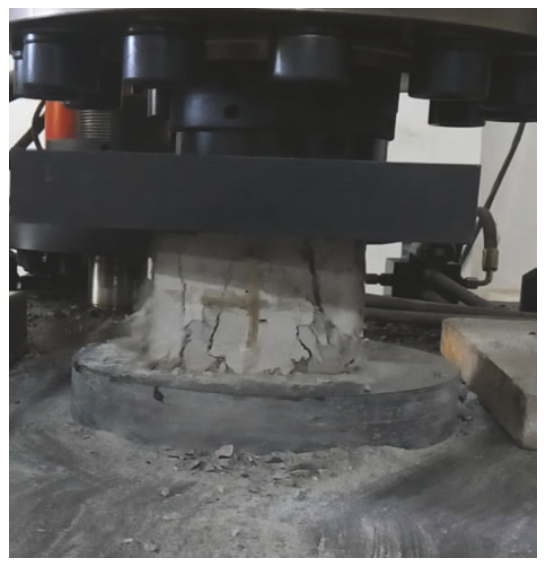

(f)

Figure 3: Failure mode of HSC specimens under uniaxial compression loads after different high temperature processes: $\left(\right.$ a) P-2-0.5, $S_{\max }=$ $0.80,0.5 N_{f}$; (b) P-2-3, $S_{\max }=0.85,0.5 N_{f}$; (c) P-5- $0.5, S_{\max }=0.90,0.25 N_{f}$; (d) P-6-3, $S_{\max }=0.85,0.75 N_{f}$; (e) P-8-2, $S_{\max }=0.90, N_{f}$; (f) critical failure state of fatigue.

TABLE 2: Appearance characteristics of HSC after exposure to high temperatures and then room temperature cooling.

\begin{tabular}{|c|c|c|c|c|c|}
\hline Temperature: ${ }^{\circ} \mathrm{C}$ & Color & Crack propagation & scaling & $\begin{array}{c}\text { Broken edges and } \\
\text { corners }\end{array}$ & Looseness \\
\hline 20 & Cinereous & None & None & None & None \\
\hline 200 & Cinereous & None & None & None & None \\
\hline $400(0.5 \mathrm{~h}, 1 \mathrm{~h})$ & Reddish & Little & Little & Little & Mild \\
\hline 600 & Grey & Some & Some & Some & A little heavy \\
\hline 800 & Offwhite & $\begin{array}{l}\text { Throughout the } \\
\text { surface }\end{array}$ & Mostly & All the cornerS & Heavy \\
\hline
\end{tabular}

strength of the HSC specimen after different high temperature processes is shown in Table 3.

3.1.4. Fatigue Life. The fatigue life of the HSC specimens under uniaxial compression cyclic loading is shown in Table 4. Since it is generally believed that the fatigue life of concrete material obeys the lognormal distribution [16, 17], the logarithm of the mean value of fatigue life obtained under the same stress level is used as the average fatigue life of specimens under this condition.
3.1.5. Fatigue Deformation. In this experiment, the maximum strain $\varepsilon_{T, \max }$ at the fatigue direction of the HSC was measured, and its relationship with the relative fatigue cycles was shown in Figure 4. It can be seen that when specimens are under fatigue load, the longitudinal fatigue total strain increases with the maximum stress level and fatigue load cycle number and its development can be divided into three stages, which is the same as the fatigue strain behavior of ordinary concrete (Zhao DF, 2002); [18, 19]. The first stage was the crack initiation stage, the fatigue strain increased rapidly from zero to the 
TABLE 3: Basic mechanical values of HSC after different high temperature processes.

\begin{tabular}{lccc}
\hline Specimen number & $f_{c}^{T}: \mathrm{Mpa}$ & $E^{T}:\left(10^{4} \mathrm{~N} / \mathrm{mm}^{2}\right)$ & $\varepsilon_{p}: 10^{-6}$ \\
\hline P-2-0.5 & 42.6 & 3.21 & 1920 \\
P-2-1 & 40.1 & 3.33 & 1999 \\
P-2-2 & 41.2 & 3.59 & 1948 \\
P-2-3 & 46.5 & 3.54 & 2076 \\
P-4-0.5 & 45.2 & 3.44 & 2515 \\
P-4-1 & 44.3 & 3.43 & 2505 \\
P-4-2 & 42.4 & 3.43 & 2631 \\
P-4-3 & 39.9 & 3.37 & 3056 \\
P-6-0.5 & 32.5 & 3.37 & 3784 \\
P-6-1 & 30.2 & 3.11 & 3101 \\
P-6-2 & 28.5 & 3.04 & 3985 \\
P-6-3 & 25.9 & 2.96 & 3624 \\
P-8-0.5 & 19.2 & 2.87 & 4203 \\
P-8-1 & 18.0 & 2.80 & 4574 \\
P-8-2 & 15.3 & 2.72 & 4799 \\
P-8-3 & 11.8 & 2.66 & 4816 \\
\hline
\end{tabular}

Note. P- $X-X$ indicates fatigue test-heating temperature-holding time, and P0 indicates $\mathrm{HSC}$ at room temperature.

TABLE 4: Test data of fatigue for HSC.

\begin{tabular}{lccc}
\hline Specimen number & \multicolumn{3}{c}{ Average fatigue life } \\
\hline P-0 & $0.9 f_{c}^{T}$ & $0.85 f_{c}^{T}$ & $0.8 f_{c}^{T}$ \\
P-2-0.5 & 4.19 & 4.83 & 5.29 \\
P-2-1 & 2.25 & 3.37 & 5.08 \\
P-2-2 & 3.16 & 4.53 & 5.01 \\
P-2-3 & 2.07 & 4.34 & 4.91 \\
P-4-0.5 & 2.74 & 3.60 & 4.74 \\
P-4-1 & 1.83 & 4.62 & 5.15 \\
P-4-2 & 2.80 & 4.83 & 4.97 \\
P-4-3 & 2.09 & 2.82 & 3.08 \\
P-6-0.5 & 2.37 & 4.65 & 5.04 \\
P-6-1 & 3.47 & 4.87 & 5.06 \\
P-6-2 & 3.52 & 4.74 & 4.96 \\
P-6-3 & 3.50 & 4.80 & 5.08 \\
P-8-0.5 & 1.49 & 2.32 & 4.49 \\
P-8-1 & 3.36 & 4.20 & 4.83 \\
P-8-2 & 3.22 & 4.02 & 4.820 \\
P-8-3 & 3.17 & 3.87 & 4.73 \\
\hline
\end{tabular}

Note. P-X-X indicates fatigue test-heating temperature-holding time, and P0 indicates $\mathrm{HSC}$ at room temperature.

steady state, the strain growth rate was large, and this stage accounted for about $10 \%$ of the whole fatigue life; that is, $N / N_{f} \leq 0.10$; the second stage was the stable crack expansion stage, the fatigue strain was linearly increasing and the growth rate was relatively stable, and it accounted for about $75 \%$ of the whole fatigue life; that is, $0.10<N / N_{f} \leq 0.85$; the third stage was the crack instability damage stage, as the fatigue strain suddenly increased, the test block quickly entered the failure stage, and the ultimate strain during failure was smaller than the ordinary concrete under uniaxle. This law is consistent with the development law given by Holmen [19].

Further analysis of Figure 4 shows that the fatigue strain of HSC was not only related to the heating temperature and holding time duration but also related to the magnitude of the stress level. When the holding time was the same and the heating temperature was different, the fatigue strain growth was small before $400^{\circ} \mathrm{C}$ but increased rapidly after $400^{\circ} \mathrm{C}$, and the fatigue strain at $800^{\circ} \mathrm{C}$ was quintuple larger that at $200^{\circ} \mathrm{C}$. It can be seen from Figures $4(\mathrm{a})-4(\mathrm{~g})$ showed that the heating temperature had a greater effect on the fatigue strain of HSC than the holding time and stress level. When the heating temperature was the same and the holding time was different, the fatigue strain of HSC increased with the stress level, but the growth trend was not obvious.

The regression equation of the fatigue strain of HSC after different high temperature processes was obtained by nonlinear multivariate regression of the measured strain, the cycle times, and stress levels:

$$
\begin{aligned}
\varepsilon_{T, \max }= & a\left(\frac{N}{N_{f}}\right)^{3}+b\left(\frac{N}{N_{f}}\right)^{2}+c\left(\frac{N}{N_{f}}\right)+d T+e t \\
& +f .
\end{aligned}
$$

In order to facilitate the engineering application and analysis, this paper analyzed the relationship between the strain and the cycle times of the HSC after the high temperature history under various stress levels and put forward a unified formula.

$$
\begin{aligned}
\text { When } S_{\max }=0.80, S_{\min }=0.10, & \\
\varepsilon_{T, m}= & \left\{768.45\left(\frac{N}{N_{f}}\right)^{3}-1007.02\left(\frac{N}{N_{f}}\right)^{2}\right. \\
+ & \left.1057\left(\frac{N}{N_{f}}\right)+6.91 T+201.55 t+2295.23\right\} \\
& \left(20^{\circ} \mathrm{C}<T \leq 800^{\circ} \mathrm{C}\right) R^{2}=0.9017 . \\
& \text { When } S_{\max }=0.85, S_{\min }=0.10, \\
\varepsilon_{T, m}= & \left\{829.58\left(\frac{N}{N_{f}}\right)^{3}-847.15\left(\frac{N}{N_{f}}\right)^{2}\right. \\
+ & \left.866.41\left(\frac{N}{N_{f}}\right)+6.02 T+481.21 t+2366.90\right\} \\
& \text { When } S_{\max }=0.90, S_{\min }=0.10, \\
\varepsilon_{T, m}= & \left\{1321.76\left(\frac{N}{N_{f}}\right)^{3}-2178.95\left(\frac{N}{N_{f}}\right)^{2}\right. \\
+ & \left.1695.13\left(\frac{N}{N_{f}}\right)+9.44 T+199.37 t+1698.39\right\}
\end{aligned}
$$$$
\left(20^{\circ} \mathrm{C}<T \leq 800^{\circ} \mathrm{C}\right) R^{2}=0.8346 \text {. }
$$ 


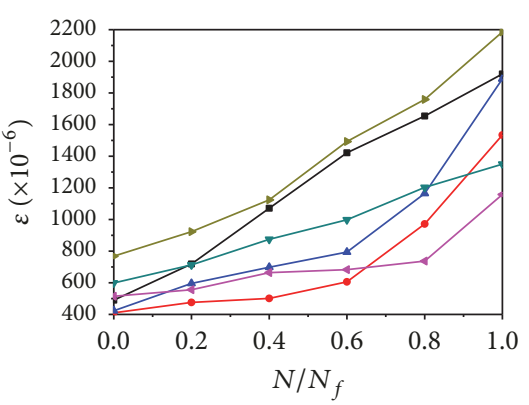

$\simeq 0.5 \mathrm{~h} S_{\max }=0.80 \multimap 0.5 \mathrm{~h} S_{\max }=0.90$

$\longrightarrow 1 \mathrm{~h} S_{\max }=0.90 \longrightarrow 2 \mathrm{~h} S_{\max }=0.80$

$\longrightarrow 2 \mathrm{~h} S_{\max }=0.85 \rightarrow 3 \mathrm{~h} S_{\max }=0.85$

(a) $200^{\circ} \mathrm{C}$

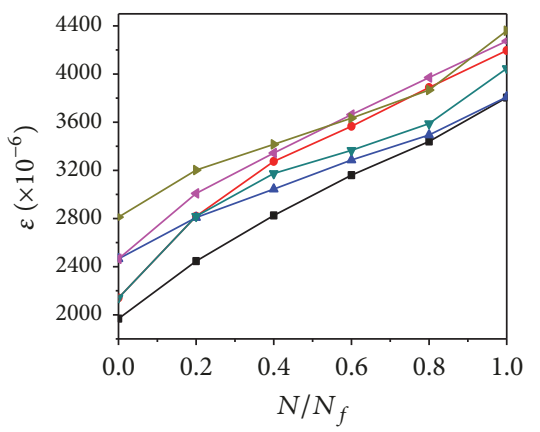

$\longrightarrow 0.5 \mathrm{~h} S_{\max }=0.85 \longrightarrow 0.5 \mathrm{~h} S_{\max }=0.90$

$\smile 1 \mathrm{~h} S_{\max }=0.85 \longrightarrow 2 \mathrm{~h} S_{\max }=0.80$

$\multimap 2 \mathrm{~h} S_{\max }=0.90 \rightarrow 3 \mathrm{~h} S_{\max }=0.80$

(c) $600^{\circ} \mathrm{C}$

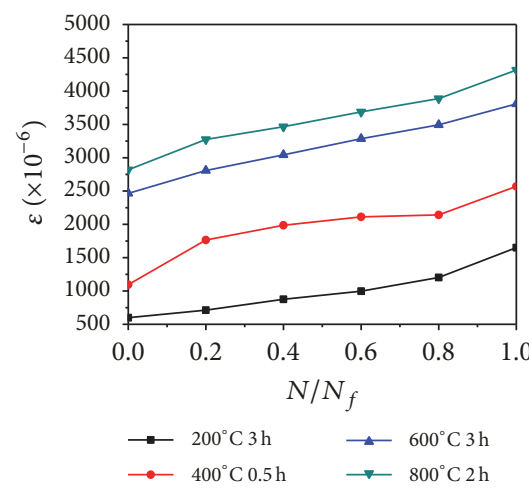

(e) $200^{\circ} \mathrm{C} \sim 800^{\circ} \mathrm{C} S_{\max }=0.80$

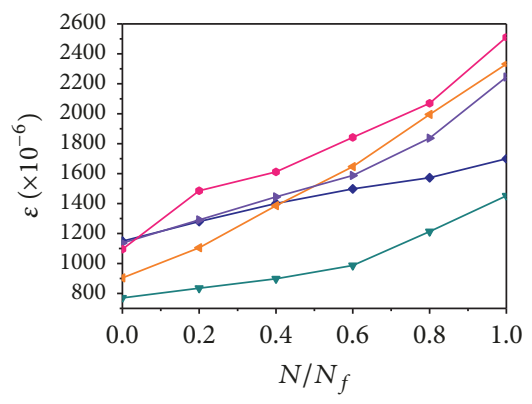

$\longrightarrow 1 \mathrm{~h} S_{\max }=0.80 \longrightarrow 1 \mathrm{~h} S_{\max }=0.85$

$\multimap 1 \mathrm{~h} S_{\max }=0.90 \longrightarrow 2 \mathrm{~h} S_{\max }=0.80$

$\longrightarrow 2 \mathrm{~h} S_{\max }=0.80$

(b) $400^{\circ} \mathrm{C}$

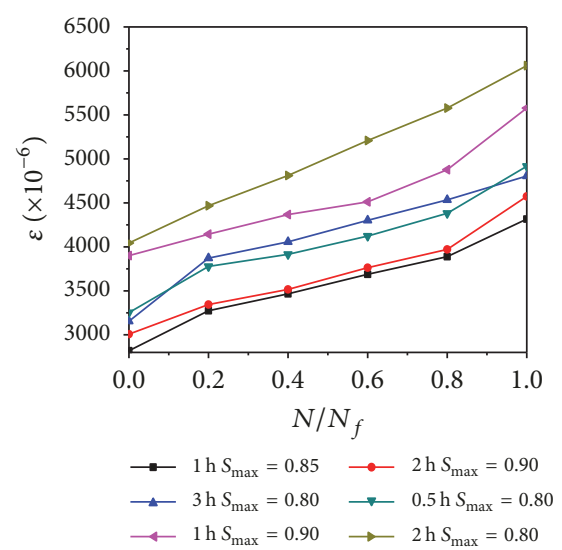

(d) $800^{\circ} \mathrm{C}$
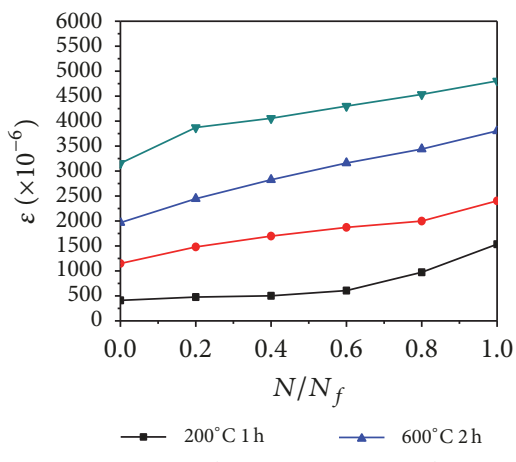

$\longrightarrow 400^{\circ} \mathrm{C} 1 \mathrm{~h} \longrightarrow 800^{\circ} \mathrm{C} 1 \mathrm{~h}$

(f) $200^{\circ} \mathrm{C} \sim 800^{\circ} \mathrm{C} S_{\max }=0.85$

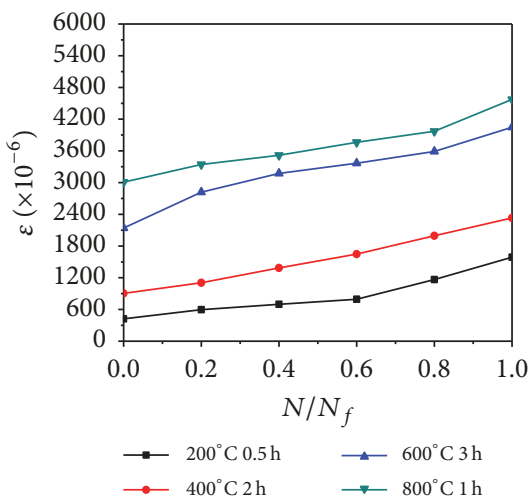

(g) $200^{\circ} \mathrm{C} \sim 800^{\circ} \mathrm{C} S_{\max }=0.90$

Figure 4: Relationship between fatigue strain and relative fatigue cycles: (a) $200^{\circ} \mathrm{C}$; (b) $400^{\circ} \mathrm{C}$; (c) $600^{\circ} \mathrm{C}$; (d) $800^{\circ} \mathrm{C}$; (e) $200^{\circ} \mathrm{C} \sim 800^{\circ} \mathrm{C}, S_{\text {max }}$ $=0.80$; (f) $200^{\circ} \mathrm{C} \sim 800^{\circ} \mathrm{C}, S_{\max }=0.85 ;$ (g) $200^{\circ} \mathrm{C} \sim 800^{\circ} \mathrm{C}, S_{\max }=0.90$. 


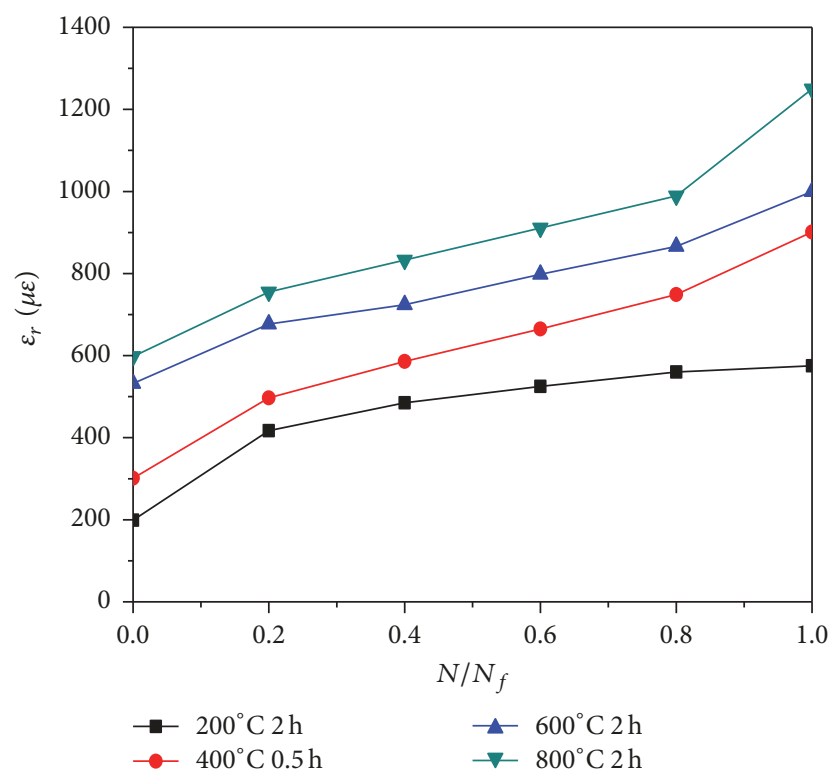

(a) $200^{\circ} \mathrm{C} \sim 800^{\circ} \mathrm{C} S_{\max }=0.90$

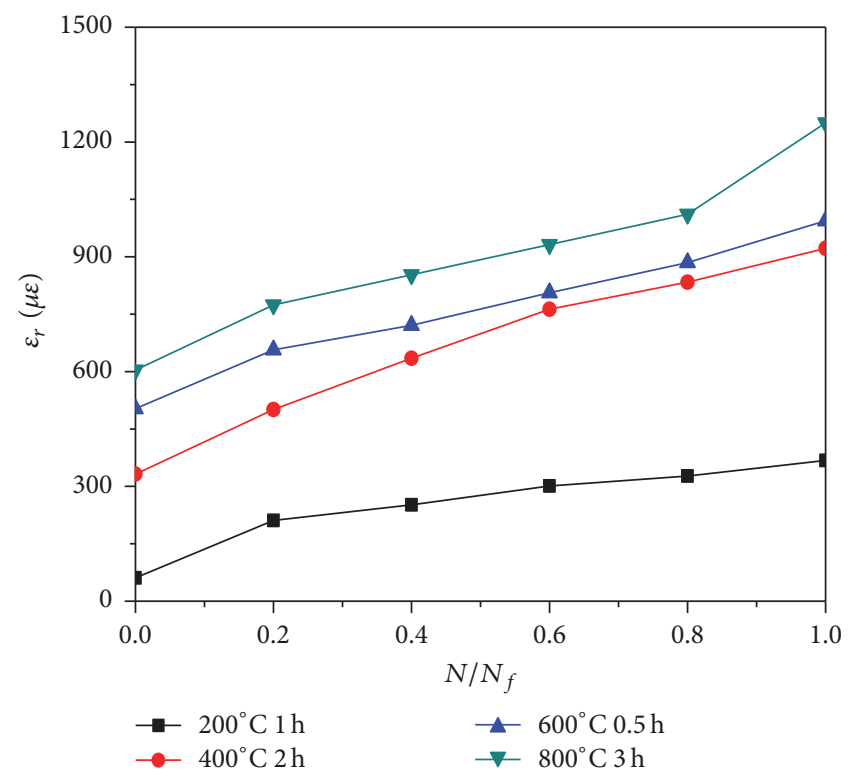

(b) $200^{\circ} \mathrm{C} \sim 800^{\circ} \mathrm{C} S_{\max }=0.85$

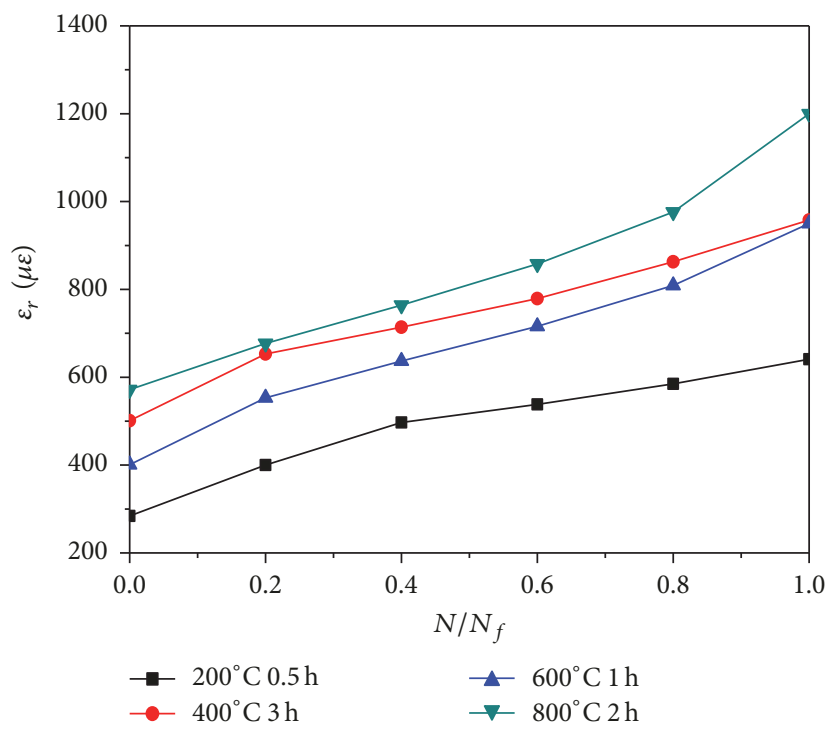

(c) $100^{\circ} \mathrm{C} \sim 900^{\circ} \mathrm{C} S_{\max }=0.80$

FIGURE 5: Relationship between the fatigue residual strain, holding time $t$, and high temperature $T$.

\subsection{Fatigue Damage}

3.2.1. Fatigue Residual Strain. It is pointed out that, with the increase of fatigue cycle times, the residual strain of concrete in uniaxial stress state was the same with total fatigue strain, which showed a three-stage development law. And the residual strain value under fatigue failure was not affected by the stress level but also had nothing to do with the loading process; it was constant $[12,15,20]$. In this paper, the uniaxial compression fatigue test of HSC after different high temperature process was carried out and the residual strain was measured. The development history is shown in Figure 5, which verifies the above conclusion.
The regression equation of the fatigue residual strain $\varepsilon_{r, T}$ of HSC and relative fatigue number $N / N_{f}$ was obtained by nonlinear regression under the number of cycles and stress levels:

$$
\varepsilon_{r, T}=a\left(\frac{N}{N_{f}}\right)^{3}+b\left(\frac{N}{N_{f}}\right)^{2}+c\left(\frac{N}{N_{f}}\right)+d t+e .
$$

In order to facilitate engineering application and analysis, this paper analyzed the relationship between the fatigue modulus and the number of cycles of HSC after the different high temperature process under various stress levels and put forward unified formulas. 


$$
\begin{aligned}
& \text { When } S_{\max }=0.80, S_{\min }=0.10, \\
& \varepsilon_{r, T}=\left\{1061.92\left(\frac{N}{N_{f}}\right)^{3}-1686.43\left(\frac{N}{N_{f}}\right)^{2}\right. \\
&+\left.1147.08\left(\frac{N}{N_{f}}\right)+2.1855 T+136.5 t+409.28\right\} \\
& \varepsilon_{r, T}=\left\{696.75\left(\frac{N}{N_{f}}\right)^{3}-1165.89\left(\frac{N}{N_{f}}\right)^{2}\right. \\
& \text { When } S_{\max }=0.85, S_{\min }=0.10, \\
&+\left.975.91\left(\frac{N}{N_{f}}\right)+1.3176 T+197.27 t+376.23\right\} \\
&+\left.725.23\left(\frac{N}{N_{f}}\right)+2.1819 T+171.39 t+471.15\right\} \\
& \varepsilon_{r, T}=\left\{571.91\left(\frac{N}{N_{f}}\right)^{3}-887.04\left(\frac{N}{N_{f}}\right)^{2}\right. \\
& \text { When } S_{\max }=0.90, S_{\min }=0.10, \\
& 200^{\circ} \mathrm{C}<T \leq 800^{\circ} \mathrm{C}\left(R^{2}=0.8992\right) .
\end{aligned}
$$

From Figure 5 and formulas (4a), (4b), and (4c) it can be seen that the residual strain of HSC under fatigue failure is related to the heating temperature and the holding time duration but not related to the magnitude of the stress level and the fatigue cycle times. And it is almost the same with the uniaxial fatigue residual strain development of ordinary concrete. The residual strains of HSC at high temperature from $200^{\circ} \mathrm{C}$ to $800^{\circ} \mathrm{C}$ are $471 \mu, 927 \mu, 997 \mu$, and $1233 \mu$, which are larger than the uniaxial fatigue residual strain of ordinary concrete. All above can be used as fatigue damage guidelines of HSC after high temperature process.

3.2.2. Fatigue Damage Based on Fatigue Residual Strain. Fatigue damage of concrete is due to its internal microcracks expansion which will lead to an unstable state, so taking the fatigue residual strain as a measure criterion of fatigue damage is scientific and reasonable. According to the basic concepts of damage mechanics, the relative residual strain is defined; that is, the residual strain $\varepsilon_{r, T}$ and fatigue failure ultimate residual strain $\varepsilon_{r, T}^{0}$ are damage variables; the damage equation is

$$
\begin{aligned}
D_{m}= & \frac{\varepsilon_{r, T}}{\varepsilon_{r, m}^{0}} \\
= & a\left(\frac{N}{N_{f}}\right)^{3}+b\left(\frac{N}{N_{f}}\right)^{2}+c\left(\frac{N}{N_{f}}\right)+d T+e t \\
& +f, \quad D_{m} \in(0,1) .
\end{aligned}
$$

TABLE 5: Fatigue life.

\begin{tabular}{lcccc}
\hline Specimen number & $D_{m}$ & $N_{e 0.9}$ & $N_{e 0.85}$ & $N_{e 0.8}$ \\
\hline P-2-0.5 & 0.835 & 2.19 & 4.46 & 5.20 \\
P-2-1 & 0.961 & 2.97 & 4.87 & 5.27 \\
P-2-2 & 0.735 & 1.88 & 4.27 & 5.03 \\
P-2-3 & 0.686 & 1.76 & 4.11 & 4.96 \\
P-4-0.5 & 0.770 & 2.01 & 4.30 & 5.11 \\
P-4-1 & 0.735 & 1.88 & 4.27 & 5.04 \\
P-4-2 & 0.746 & 1.92 & 4.30 & 5.09 \\
P-4-3 & 0.739 & 1.89 & 4.28 & 5.06 \\
P-6-0.5 & 0.415 & 1.53 & 3.77 & 4.62 \\
P-6-1 & 0.399 & 1.51 & 3.74 & 4.45 \\
P-6-2 & 0.418 & 1.53 & 3.78 & 4.64 \\
P-6-3 & 0.402 & 1.51 & 3.70 & 4.60 \\
P-8-0.5 & 0.394 & 1.50 & 3.66 & 4.39 \\
P-8-1 & 0.389 & 1.49 & 3.62 & 4.28 \\
P-8-2 & 0.393 & 1.50 & 3.66 & 4.34 \\
P-8-3 & 0.395 & 1.50 & 3.67 & 4.33 \\
\hline
\end{tabular}

Note. $\mathrm{P}-\mathrm{X}-\mathrm{X}$ indicates fatigue test-heating temperature- holding time, and $\mathrm{P}-$ 0 indicates $\mathrm{HSC}$ at room temperature.

TABLE 6: Distribution table of relative errors (\%).

\begin{tabular}{lccc}
\hline Specimen number & $E_{0.9}$ & $E_{0.85}$ & $E_{0.8}$ \\
\hline P-2-0.5 & 2.667 & 32.34 & 2.36 \\
P-2-1 & 6.01 & 7.51 & 5.19 \\
P-2-2 & 9.18 & 1.61 & 2.44 \\
P-2-3 & 35.77 & 14.17 & 4.64 \\
P-4-0.5 & 9.84 & 6.93 & 0.78 \\
P-4-1 & 32.86 & 11.59 & 1.41 \\
P-4-2 & 8.13 & 52.48 & 65.26 \\
P-4-3 & 20.25 & 7.96 & 0.405 \\
P-6-0.5 & 55.91 & 22.59 & 8.70 \\
P-6-1 & 57.10 & 21.10 & 10.28 \\
P-6-2 & 56.29 & 21.25 & 8.66 \\
P-6-3 & 1.34 & 59.48 & 2.45 \\
P-8-0.5 & 55.36 & 12.86 & 9.11 \\
P-8-1 & 53.73 & 9.95 & 11.20 \\
P-8-2 & 52.68 & 5.43 & 8.25 \\
P-8-3 & 51.61 & 1.87 & 5.87 \\
\hline
\end{tabular}

Note. Exx in this table is the absolute value of the relative error.

Figure 6 shows the relationship between the damage variables of HSC and the relative fatigue cycle times after different high temperature process. The fatigue damage model can be used to analyze the accumulated fatigue damage of HSC under low temperature uniaxial compression after different high temperature processes.

The remaining fatigue life of the HSC under low cyclic uniaxial compression after suffering different high temperature process was predicted, which was shown in Table 5. Compared to the test results in Table 4, the relative error distribution of the fatigue life of HSC under uniaxial compression after suffering different high temperature processes can be obtained as shown in Table 6 . 


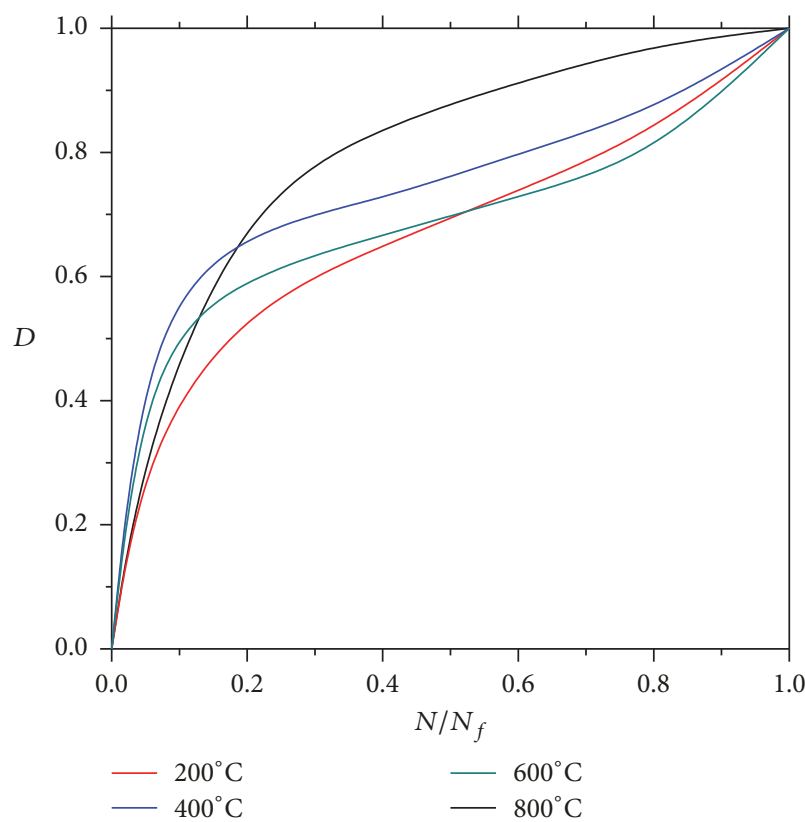

(a) $S_{\max }=0.90$

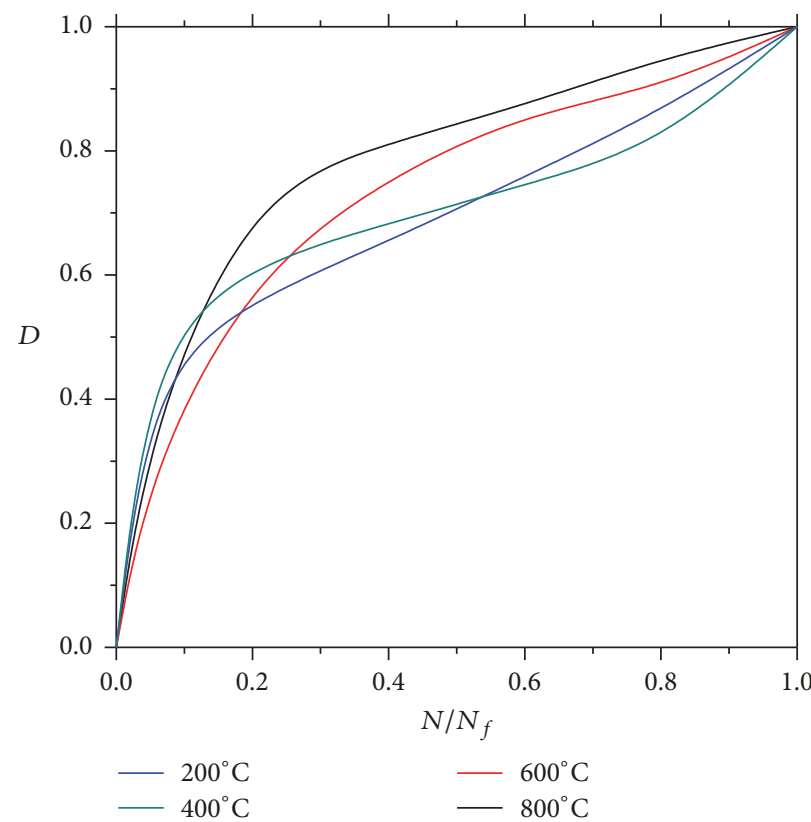

(b) $S_{\max }=0.85$

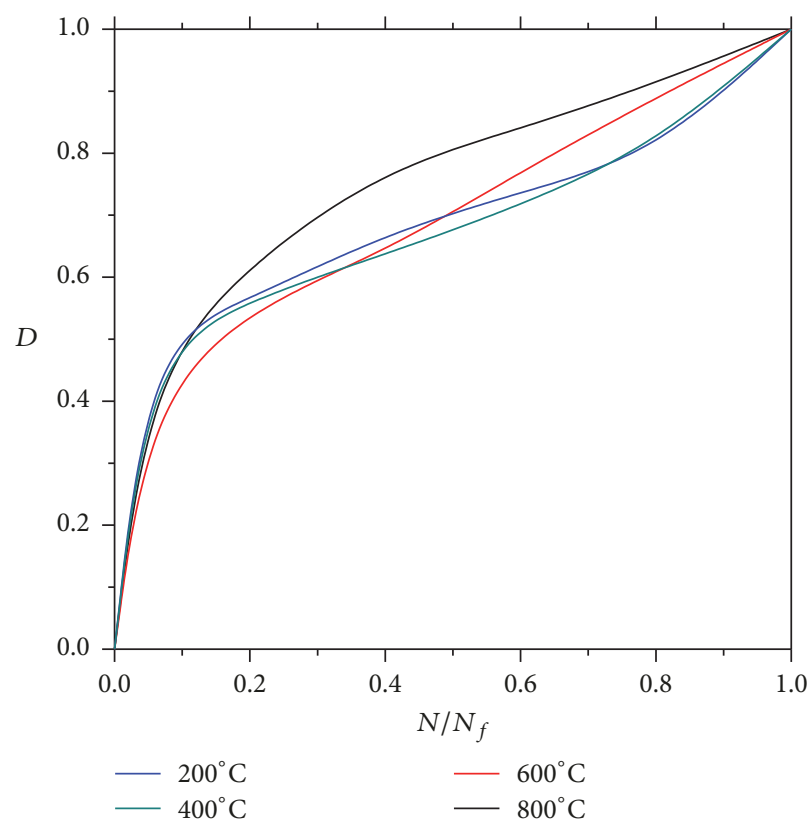

(c) $S_{\max }=0.80$

FIgURE 6: Relationship between damage and relative fatigue cycles of HSC with high temperature process.

It can be seen from the calculated results that, among the absolute values of the relative error between predicted and measured values, the values which are less than $30 \%$ account for more than $85 \%$ of the total. With the huge difficulties in testing, the numerous influential factors, and the big discrepancy of experimental data taken into consideration, the predicted value was satisfactory for the low cyclic uniaxial compressive fatigue test of HSC after suffering different high temperature processes. Thus, an effective method was developed to predict the fatigue residual life of HSC after different high temperature processes.

The damage equation at different stress levels from formulas (4a), (4b), and (4c) to (5) and Figure 6 was obtained by nonlinear regression under the number of cycles and stress levels. 


$$
\begin{aligned}
& \text { When } S_{\max }=0.80, S_{\min }=0.10, \\
D_{m}= & \left\{3.3141\left(\frac{N}{N_{f}}\right)^{3}-5.6933\left(\frac{N}{N_{f}}\right)^{2}\right. \\
+ & 3.2574\left(\frac{N}{N_{f}}\right)-0.001\left(\frac{T}{100}\right)+0.0029 t \\
+ & 0.1423\} \quad 20^{\circ} \mathrm{C}<T \leq 800^{\circ} \mathrm{C}\left(R^{2}=0.9027\right) . \\
& \text { When } S_{\max }=0.85, S_{\min }=0.10, \\
D_{m} & =\left\{3.3604\left(\frac{N}{N_{f}}\right)^{3}-6.0469\left(\frac{N}{N_{f}}\right)^{2}\right. \\
+ & 0.1152\} \quad 3.6014\left(\frac{N}{N_{f}}\right)-0.004\left(\frac{T}{100}\right)+0.0038 t \\
+ & 0.1036\} \quad 20^{\circ} \mathrm{C}<T \leq 800^{\circ} \mathrm{C}\left(R^{2}=0.8844\right) . \\
& =\left\{3.6074\left(\frac{N}{N_{f}}\right)^{3}-6.3556\left(\frac{N}{N_{f}}\right)^{2}\right. \\
& \text { When } S_{\max }=0.90, S_{\min }=0.10, \\
& \left\{\begin{array}{c}
N_{f} \\
+
\end{array}\right) .003\left(\frac{T}{100}\right)+0.0133 t
\end{aligned}
$$

\section{Conclusions}

The color of HSC turns lighter after the high temperature processes. At about $500^{\circ} \mathrm{C}$, the specimens are light gray and parts of them have a serious burst; the cross-section is relatively rough and some holes and cracks exist in the broken specimens. After $800^{\circ} \mathrm{C}$, the specimens' appearance are offwhite, some coarse cracks appear, and some even run throughout the specimen. The structure of the specimen is relatively loose.

The maximum longitudinal total strain of the HSC after exposure to high temperature processes under low cyclic uniaxial compressive loading is in accordance with the threestage development law. The second stage is the stable crack propagation stage, which accounts for about $75 \%$ of the whole fatigue life. The formulas to figure out the longitudinal total strains at each stage were given. Compared with the stress level, the effect of high temperature process on the fatigue strain of HSC is more significant, especially the influence of heating temperature.

The relative residual strain was defined as the damage variable, and the fatigue damage model of HSC after different high temperature processes, under low cyclic uniaxial compressive loading, was established. According to the damage model established by the relative residual strain, the fatigue life of high strength concrete was predicted. More than $85 \%$ of the absolute values of the relative error between predicted and measured values are less than $30 \%$, and the result is satisfactory.

\section{Data Availability}

The data used to support the findings of this study are available from the corresponding author upon request.

\section{Conflicts of Interest}

The authors declare that they have no conflicts of interest.

\section{Acknowledgments}

The present work was supported by the National Natural Science Foundation of China (no. 51378045). The authors gratefully acknowledge the support.

\section{References}

[1] A. H. Al-Gadhib, M. H. Baluch, A. Shaalan, and A. R. Khan, "Damage model for monotonic and fatigue response of high strength concrete," International Journal of Damage Mechanics, vol. 9, no. 1, pp. 57-78, 2000.

[2] M. Ayman and A. E. Mohamed, "Mechanical properties of high strength concrete with scrap tire rubber," Construction and Building Materials, vol. 93, pp. 249-256, 2015.

[3] F.-P. Cheng, V. K. R. Kodur, and T.-C. Wang, "Stress-strain curves for high strength concrete at elevated temperatures," Journal of Materials in Civil Engineering, vol. 16, no. 1, pp. 84-90, 2004.

[4] Z. J. He and Y. P. Song, "Multiaxial tensile-compressive mechanical behaviour of plain high-strength high-performance concrete," Engineering Mechanics, vol. 67, pp. 190-195, 2010.

[5] J. L. Liu, J. Y. Xu, and W. B. Ren, "Mechanical properties of high strength concrete under impact loading," Bulletin Chinese Ceramic Society, vol. 35, pp. 261-266, 2016.

[6] M. Ghandehari, A. Behnood, and M. Khanzadi, "Residual mechanical properties of high-strength concretes after exposure to elevated temperatures," Journal of Materials in Civil Engineering, vol. 22, no. 1, Article ID 004001QMT, pp. 59-64, 2010.

[7] M. Amin and K. Abu El-Hassan, "Effect of using different types of nano materials on mechanical properties of high strength concrete," Construction and Building Materials, vol. 80, pp. 116$124,2015$.

[8] F. Saber and N. Mahdi, "Mechanical properties and durability of high-strength concrete containing macro-polymeric and polypropylene fibers with nano-silica and silica fume," Construction and Building Materials, vol. 132, pp. 170-187, 2017.

[9] V. Afroughsabet and T. Ozbakkaloglu, "Mechanical and durability properties of high-strength concrete containing steel and polypropylene fibers," Construction and Building Materials, vol. 94, pp. 73-82, 2015.

[10] J. Xiao, Z. Li, Q. Xie, and L. Shen, "Effect of strain rate on compressive behaviour of high-strength concrete after exposure to elevated temperatures," Fire Safety Journal, vol. 83, pp. 25-37, 2016. 
[11] P. Y. Lv and Y. P. Song, "Tensile mechanical behaviour of concrete under different temperatures," Engineering Mechanics, vol. 20, pp. 80-85, 2003.

[12] P. Y. Lv, Experimental Study on Dynamic Strength and Deformation of Concrete Under Uniaxial and Blaxial Action [Ph.D. thesis], Dalian University of Technology, Dalian, China, 2002.

[13] X. G. Zhou and J. L. Wu, "Preliminary research on fatigue behavior of concrete after exposed to high temperature," Industrial Constructions, vol. 26, pp. 33-36, 1996.

[14] D. Zhao and M. Liu, "Experimental study on residual strength and nondestructive testing of high strength concrete after high temperature," Jianzhu Jiegou Xuebao/Journal of Building Structures, vol. 36, pp. 365-372, 2015.

[15] J. F. Xu, Experimental Investigation of the Complete Stressstrain Curve of High Strength Concrete, [Ph.D. thesis], Tsinghua University, Beijing, China, 1986.

[16] H. K. Cheong and H. Zeng, "Stress-strain relationship for concrete confined by lateral steel reinforcement," ACI Materials Journal, vol. 99, no. 3, pp. 250-255, 2002.

[17] J. T. McCall, "Probability of fatigue failure of plain concrete," ACI Journal Proceedings, vol. 55, no. 8, pp. 233-244, 1958.

[18] R. M. Wang, Y. P. Song, and G. P. Zhao, "Study on fatigue properties of concrete under compression," Engineering Mechanics, vol. 24, pp. 38-47, 1991.

[19] J. O. Holmen, "Fatigue of concrete by constant and variable amplitude tests," ACI Journal, vol. 75, no. 4, pp. 71-110, 1982.

[20] D. Zhao, H. Gao, H. Liu, P. Jia, and J. Yang, "Fatigue Properties of Plain Concrete under Triaxial Tension-CompressionCompression Cyclic Loading," Shock and Vibration, vol. 2017, Article ID 9351820, 10 pages, 2017. 


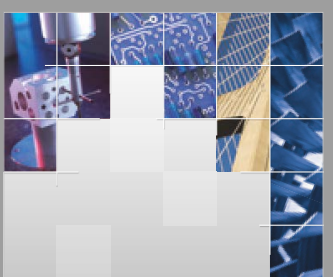

\section{Enfincering}
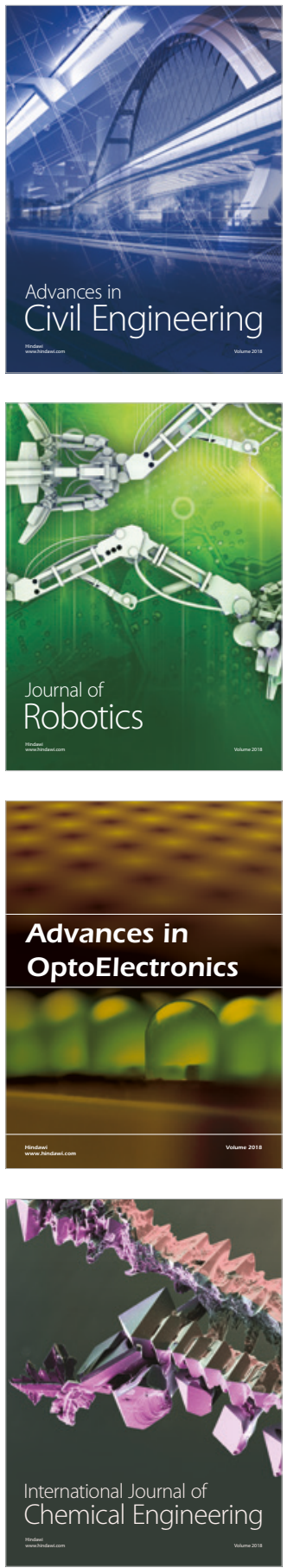

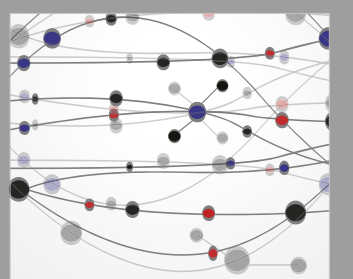

\section{Rotating \\ Machinery}

The Scientific World Journal

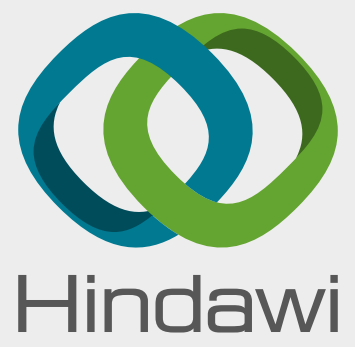

Submit your manuscripts at

www.hindawi.com
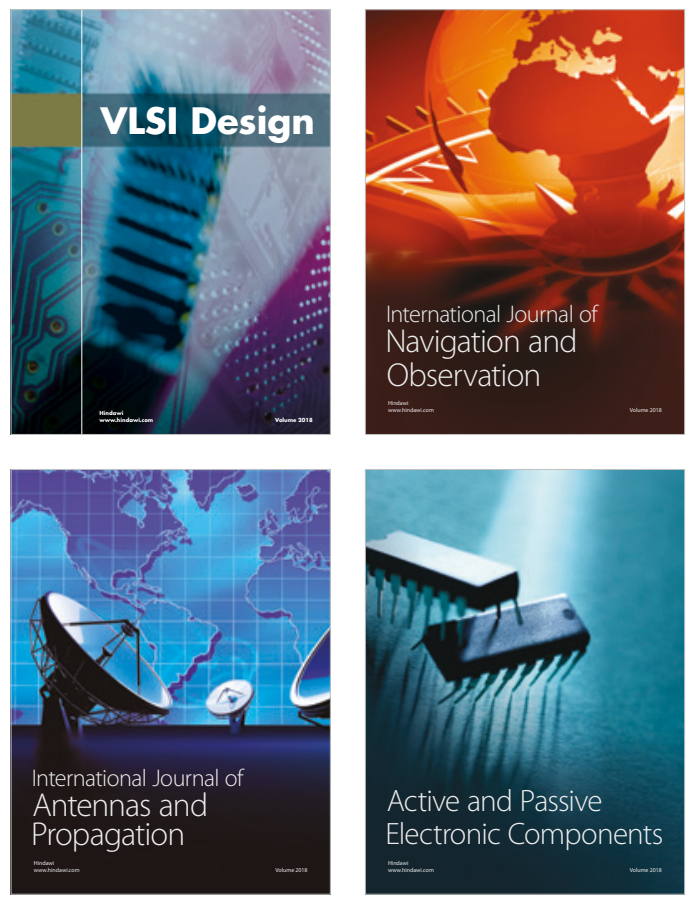
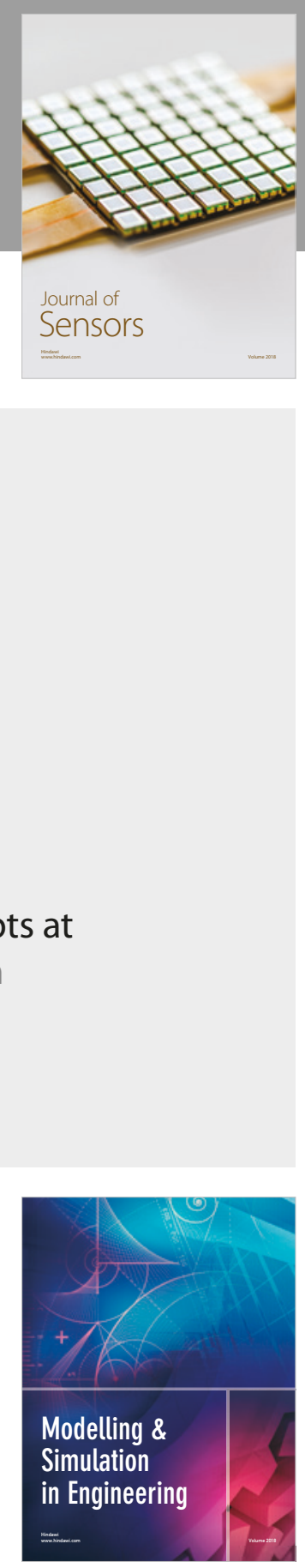

\section{Advances \\ Multimedia}
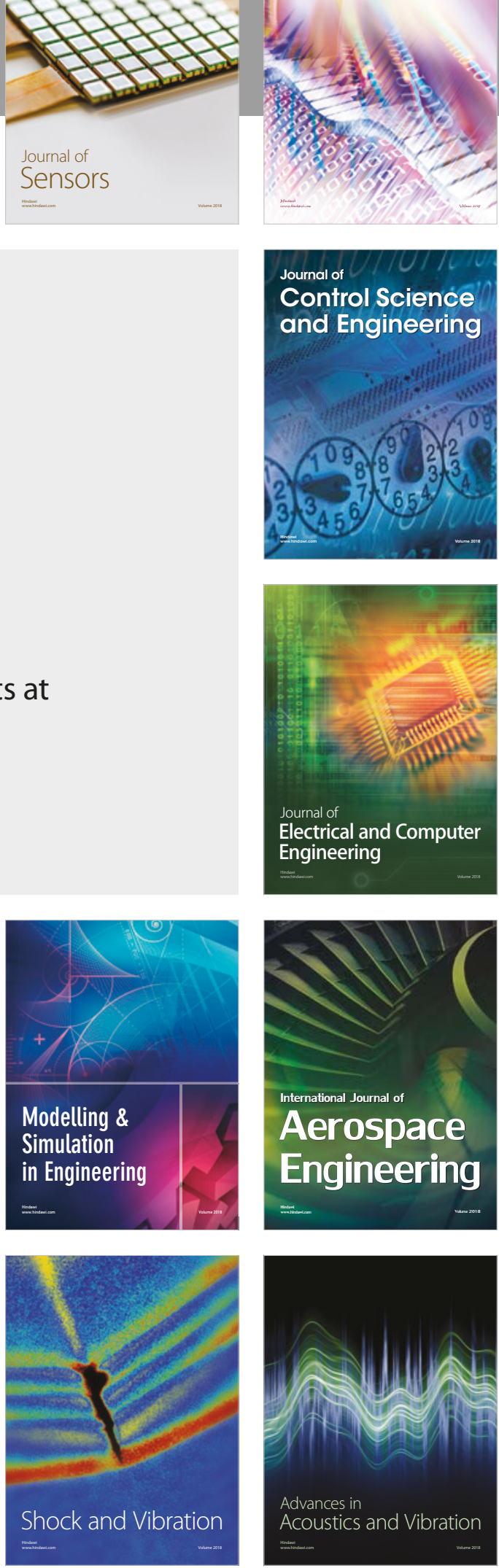